\title{
An ensemble Kalman filter system with the Stony Brook Parallel Ocean Model v1.0
}

Shun Ohishi ${ }^{1,2,3}$, Tsutomu Hihara ${ }^{4}$, Hidenori Aiki ${ }^{3,5}$, Joji Ishizaka ${ }^{3}$, Yasumasa Miyazawa ${ }^{5}$, Misako Kachi $^{6}$, Takemasa Miyoshi ${ }^{1,2,7}$

$5 \quad{ }^{1}$ RIKEN Center for Computational Science, Kobe, 6500047, Japan

${ }^{2}$ RIKEN Cluster for Pioneering Research, Kobe, 6500047, Japan

${ }^{3}$ Institute for Space-Earth Environmental Research, Nagoya University, Nagoya, 4648601, Japan

${ }^{4}$ Japan Fisheries Information Service Center, Tokyo, 1040055, Japan

${ }^{5}$ Application Laboratory, Japan Agency for Marine-Earth Science and Technology, Yokohama, 2360001, Japan

10 Earth Observation Research Center, Japan Aerospace Exploration Agency, Tsukuba, 3058505, Japan

${ }^{7}$ RIKEN Interdisciplinary Theoretical and Mathematical Sciences Program (iTHEMS), Kobe, 6500047, Japan

Correspondence to: Shun Ohishi (hun.ohishi@riken.jp) and Takemasa Miyoshi (takemasa.miyoshi@riken.jp)

\begin{abstract}
This study develops an ensemble Kalman filter (EnKF)-based regional ocean data assimilation system, in which the local ensemble transform Kalman filter (LETKF) is implemented with the Stony Brook Parallel Ocean Model (sbPOM)

15 version 1.0 to assimilate satellite and in-situ observations at a daily frequency. A series of sensitivity experiments are performed with various settings of the incremental analysis update (IAU) and covariance inflation methods, for which the relaxation-to-prior perturbations and spread (RTPP and RTPS, respectively) and multiplicative inflation (MULT) are considered. We evaluate the geostrophic balance and the analysis accuracy compared with the control experiment in which the IAU and covariance inflation are not applied. The results show that the IAU improves the geostrophic balance, degrades

20 the accuracy, and reduces the ensemble spread, and that the RTPP and RTPS have the opposite effect. The experiment using the combination of the IAU and RTPP results in significant improvement for both balance and accuracy when the RTPP parameter is $0.8-0.9$. The combination of the IAU and RTPS improves the balance when the RTPS parameter is $\leq 0.8$ and increases the accuracy for the parameter values between 1.0 and 1.1, but the balance and accuracy are not improved significantly at the same time. The experiments with MULT do not demonstrate sufficient skill in maintaining the balance

25 and reproducing the surface flow field regardless of whether the IAU is applied or not. Therefore, the combination of the IAU and RTPP with the parameter of $0.8-0.9$ is found to be the best setting for the EnKF-based ocean data assimilation system.
\end{abstract}


Short summary (493 character). We develop an ensemble Kalman filter-based regional ocean data assimilation system, in

30 which satellite and in-situ observations are assimilated at a daily frequency. We find the best setting for dynamical balance and analysis accuracy based on sensitivity experiments on how to inflate the ensemble spread and how to apply the analysis update to the model evolution. This study has a broader impact on more general data assimilation systems in which the initial shocks are a significant issue.

\section{1. Introduction}

The ensemble Kalman filter (EnKF; Evensen, 1994, 2003) estimates optimal analyses using model forecasts and observations with their error covariance. The EnKF has advantages in including flow-dependent forecast errors from an ensemble of model forecasts and in its relative ease of implementation with various models. Therefore, various EnKF-based ocean data assimilation systems have been developed thus far (cf. Table 1).

The number of observations has increased dramatically with enhanced observations of temperature and salinity in the ocean interior by Argo profiling floats, and measurements of sea surface temperature, salinity, and height (SST, SSS, and SSH, respectively) by satellites. The geostationary satellite Himawari-8 (Bessho et al., 2016; Kurihara et al., 2016) has an infrared sensor observing SSTs in the Pacific region since July 2015, although there are missing values where cloud obscures the sea surface. The geostationary orbit and short observation interval allow Himawari- 8 to provide better daily coverage within the observation area than a polar orbiting satellite with a microwave sensor, such as the Global Change Observation Mission-Water (GCOM-W; https://gportal.jaxa.jp/gpr), which can capture SSTs even in cloudy regions. Satellite SSS observations by Soil Moisture and Ocean Salinity (SMOS) started in June 2010, and previous studies demonstrated their positive impacts with their ocean data assimilation systems to better represent the ocean interior structure such as mixed and barrier layers, low salinity water caused by river discharge, and prediction of the El Niño-Southern Oscillation (ENSO;

50 Chakraborty et al., 2014; Hackert et al., 2014; Toyoda et al., 2015). The Surface Water and Ocean Topography (SWOT; https://swot.jpl.nasa.gov/) satellite that has a new type of altimeter observing SSH anomalies (SSHAs) in two dimensions over a $120 \mathrm{~km}$ wide swath is scheduled for launch in 2022.

To take advantage of such enhanced observations, frequent data assimilation is important. Here, dynamical imbalances in the analysis field may cause an initial shock with high-frequency gravity waves and may degrade the analysis accuracy. He et al. (2020) described the relationship between the assimilation interval and accuracy using an atmospheric data assimilation system. As seen in Table 1, most of the recent ocean data assimilation systems have an assimilation interval longer than 5 days: in particular, 5- and 7-day assimilation intervals are employed in the existing ocean reanalysis datasets of the Predictive ocean atmosphere model for the Australia Ensemble Ocean Data Assimilation System (PEODAS; Yin et al., 
2011) and TOPAZ4 (Sakov et al., 2012), respectively. The PEODAS assimilates only in-situ temperature and salinity data, 60 whereas the TOPAZ4 uses all types of observations but with inflation of observation errors. Although ocean data assimilation systems constructed by Karspeck et al. (2013) and Miyazawa et al. (2012) have short assimilation intervals of 1 and 2 days, respectively, the former assimilates only in-situ temperature and salinity data, and the latter conducts a data assimilation experiment for a short period of 20 days. Therefore, the existing systems might mitigate the effects of the initial shock by using the longer assimilation interval, inflating observation errors, and reducing the number of assimilated observations.

The incremental analysis update (IAU; Bloom et al., 1996; see Sect. 2.1) has been proposed to reduce noise from high-frequency gravity waves associated with the initial shock. Covariance relaxation methods such as relaxation-to-prior perturbations and spread [RTPP (Zhang et al., 2004) and RTPS (Whitaker and Hamill, 2012), respectively; see Sect. 2.3], in which the analysis ensemble perturbations are relaxed towards the forecast ensemble perturbations, should also mitigate the initial shock (Houtekamer and Zhang, 2016; Ying and Zhang, 2015). Therefore, this study aims to develop an EnKF-based ocean data assimilation system with a frequent assimilation interval of 1 day for taking advantage of frequent satellite observations, and to explore the optimal settings by performing sensitivity experiments with various settings of the IAU and covariance inflation methods.

This paper is organized as follows. Section 2 describes data and methods about IAU, RTPP, and other schemes and

75 how to evaluate geostrophic balance and accuracy relative to observations. The details of the EnKF-based ocean data assimilation system and sensitivity experiment are described in Sect. 3. Section 4 presents the results for geostrophic balance and accuracy in the sensitivity experiments. Finally, Sect. 5 provides a summary.

\section{Data and Methods}

80 In this section, we provide details of the methods used to alleviate some of the problems associated with high frequency assimilation. Section 2.1 presents the IAU designed to cut off noise from high-frequency gravity waves, and Sect. 2.2 describes perturbed boundary conditions. Covariance inflation methods to prevent underestimation of ensemble-based forecast error covariance by various factors such as the limited ensemble size and model imperfections are introduced in Sect. 2.3, and the methods used to evaluate geostrophic balance and accuracy relative to observations in Sect. 2.4.

\subsection{IAU}

In this study, we implement the IAU (Bloom et al., 1996) based on existing ocean data assimilation systems (Balmaseda et al., 2015; Martin et al., 2015). The procedure for one assimilation cycle is as follows: (i) conduct model integration up to the 
middle of an assimilation window; (ii) assimilate observations within the window and save the analysis increments in 90 temperature, salinity, and horizontal velocity; and (iii) conduct model integration over the assimilation window adding the increments equally distributed to each timestep. The computational costs for the model integration are 1.5 times those for the standard method where the analyses performed at the beginning of the window are used for the model initial conditions.

\subsection{Perturbed boundary conditions}

95 Following previous studies (Kunii and Miyoshi, 2012; Penny et al., 2013; Torn et al., 2006), atmospheric and lateral boundary conditions are artificially perturbed for each ensemble member. Atmospheric forcing of the $i$ th ensemble member at a time $t, \boldsymbol{w}^{(i)}(t)$, is given by

$\boldsymbol{w}^{(i)}(t)=\boldsymbol{w}(t)+\alpha\left(\boldsymbol{w}\left(t+\delta t_{i}\right)-\frac{1}{n} \sum_{i=1}^{n} \boldsymbol{w}\left(t+\delta t_{i}\right)\right)$,

where $\boldsymbol{w}(t)$ is atmospheric forcing at a time $t, \alpha(=0.2)$ is an arbitrary constant, $\boldsymbol{w}\left(t+\delta t_{i}\right)$ is atmospheric forcing at the same time as $\boldsymbol{w}(t)$ but in a different year, and $n(=100)$ is the ensemble size. Here, the year in $\boldsymbol{w}\left(t+\delta t_{i}\right)$ is changed every month. As is clear from Eq. (1), the ensemble mean of the atmospheric forcing $\boldsymbol{w}^{(i)}(t)$ is equivalent to $\boldsymbol{w}(t)$.

Lateral boundary conditions for each ensemble member are obtained from a monthly-mean global ocean reanalysis dataset for different years. Namely, the ensemble mean of the lateral boundary condition corresponds to a monthly climatology. These perturbed atmospheric and lateral boundary conditions play a role equivalent to additive inflation (Houtekamer and Zhang, 2016).

\subsection{Covariance inflation methods}

Three covariance inflation methods [multiplicative inflation (MULT), RTPP, and RTPS] are adopted in this study. MULT inflates forecast error covariance $P^{f}$ by a factor of $\rho(>1)$ :

$P_{\text {inf }}^{f}=\rho P_{\text {orig }}^{f}$,

115 where the subscripts inf and orig denote inflated and original (i.e., before inflation), respectively. Both RTPP and RTPS restore the analysis ensemble perturbation towards the forecast ensemble perturbations maintaining the analysis ensemble mean, as represented by 
$\boldsymbol{X}_{\text {inf }}^{\boldsymbol{a}}=\alpha_{R T P P} \boldsymbol{X}^{\boldsymbol{f}}+\left(1-\alpha_{R T P P}\right) \boldsymbol{X}_{\text {orig }}^{\boldsymbol{a}}$ and

$\boldsymbol{X}_{\text {inf }}^{a(i)}=\frac{\alpha_{R T P S} \sigma^{f(i)}+\left(1-\alpha_{R T P S}\right) \sigma_{\text {orig }}^{a(i)}}{\sigma_{\text {orig }}^{a(i)}} \boldsymbol{X}_{\text {orig }}^{a(i)}$.

Here, $\boldsymbol{X}\left[=\left(\boldsymbol{x}^{(\mathbf{1})}-\overline{\boldsymbol{x}}, \ldots, \boldsymbol{x}^{(i)}-\overline{\boldsymbol{x}}, \ldots, \boldsymbol{x}^{(\boldsymbol{n})}-\overline{\boldsymbol{x}}\right)\right]$ is the ensemble perturbation matrix whose $i$ th column consists of the perturbations of the $i$ th ensemble member, where $x^{(i)}$ and $\bar{x}$ are the state vector of the $i$ th ensemble member and ensemble mean, the superscripts $a$ and $f$ denote analysis and forecast, and $\alpha_{R T P P}$ and $\alpha_{R T P S}$ are the relaxation parameters in the RTPP and RTPS, respectively. $\sigma^{(i)}$ is the ensemble spread of $i$ th variable of state vector $\boldsymbol{x}$, as represented by

$\sigma^{(i)}=\sqrt{(n-1)^{-1} \boldsymbol{X}^{(i)}\left(\boldsymbol{X}^{(i)}\right)^{T}}$.

In the RTPP and RTPS, the relaxation parameters are generally defined between 0 and 1 , where $\alpha_{R T P P}=\alpha_{R T P S}=0$ corresponds to no inflation, and $\alpha_{R T P P}=\alpha_{R T P S}=1$ corresponds that the analysis ensemble spread is inflated to be equivalent to the forecast ensemble spread. The RTPP and RTPS are thought to have side effects in maintaining the dynamic balance (Houtekamer and Zhang, 2016; Ying and Zhang, 2015).

\subsection{Validation}

\section{$135 \quad$ 2.4.1 Nonlinear balance equation (NBE)}

Writing the geostrophic balance equation in terms of analysis increments, we obtain

$f \boldsymbol{k} \times \delta \boldsymbol{u}=-g \boldsymbol{\nabla}_{\boldsymbol{h}} \delta \eta$

140 where $f$ is the vertical component of the Coriolis parameter, $\boldsymbol{k}$ is a unit vector in the vertical upward direction, $\delta$ is the analysis increment, $\boldsymbol{u}$ is the horizontal velocity at the sea surface, $g\left(=9.8 \mathrm{~m} \mathrm{~s}^{-2}\right)$ is the gravitational acceleration, $\boldsymbol{\nabla}_{\boldsymbol{h}}=$ $(\partial / \partial x, \partial / \partial y)$ is the horizontal gradient operator, and $\eta$ is the SSH. By taking $\partial / \partial x$ of the $x$-component of Eq. (6) plus $\partial / \partial y$ of the $y$-component, Eq. (6) can be reduced to the nonlinear balance equation (NBE; Shibuya et al., 2015; Zhang et al., 2001): 
https://doi.org/10.5194/gmd-2022-40

Preprint. Discussion started: 4 March 2022

(c) Author(s) 2022. CC BY 4.0 License.

(c) (i)

$-f \delta \zeta+\beta \delta u+g \nabla_{h}^{2} \delta \eta=0$,

where $\zeta(=\partial v / \partial x-\partial u / \partial y)$ is the relative vorticity at the sea surface and $\beta(=\partial f / \partial y)$ is the planetary vorticity gradient. If geostrophic balance is not satisfied in the analysis field, there is an absolute residual of the NBE, $\triangle N B E$ :

150

$\triangle N B E \equiv a b s\left(-f \delta \zeta+\beta \delta u+g \nabla_{h}^{2} \delta \eta\right)$,

where abs denotes taking the absolute value. Smaller (larger) $\triangle N B E$ indicates more (less) geostrophic balance in the analysis field.

\subsubsection{Improvement ratio (IR)}

To compare the geostrophic balance and accuracy among sensitivity experiments using a statistical method, we calculate improvement ratios (IRs) of area-averaged $\triangle N B E$ and root mean square deviations (RMSDs) relative to observations as represented by

160

$$
\begin{aligned}
& I R=\frac{(\Delta N B E)_{C T L}-(\Delta N B E)_{E X P}}{(\Delta N B E)_{C T L}} \times 100 \text { and } \\
& I R=\frac{(R M S D)_{C T L}-(R M S D)_{E X P}}{(R M S D)_{C T L}} \times 100
\end{aligned}
$$

respectively. The subscripts CTL and EXP indicate control and sensitivity experiments, respectively. Significant improvement and degradation are detected by the bootstrap method with 10,000 cycles and a 99\% confidence level.

\subsubsection{Observations}

To validate the accuracy of a sensitivity experiment, we use observational gridded SSH and SSHA datasets from Archiving Validation and Interpretation of Satellite Oceanographic data (AVISO; Ducet et al., 2000) with horizontal resolution of $0.25^{\circ}$,

170 in-situ surface horizontal velocity from surface drifting buoys of the Global Drifter Program (Elipot et al., 2016), in-situ temperature and salinity in the depth range $1-525 \mathrm{~m}$, and horizontal velocity in the depth range $8-36 \mathrm{~m}$ at $144.6^{\circ} \mathrm{E}, 32.3^{\circ} \mathrm{N}$ south of the Kuroshio Extension (KE) from the Kuroshio Extension Observatory (KEO) buoy (https://www.pmel.noaa.gov/ocs/; see Fig. 5a). The AVISO dataset is not an independent observational dataset because satellite SSHAs are used for the assimilation in this study, whereas the surface drifter and KEO buoys are independent. 
175 Although validation in the ocean interior might not be sufficient, this is due to the limitation of available independent observations.

\section{EnKF-based ocean data assimilation system}

\subsection{Ocean model}

180 The sigma-coordinate regional ocean model used in this study is based on the Stony Brook Parallel Ocean Model (sbPOM; Mellor, 2002; Jordi and Wang, 2012) version 1.0, and constructed for the northwestern Pacific region $\left[117^{\circ} \mathrm{E}-180^{\circ}, 15^{\circ}-\right.$ $50^{\circ} \mathrm{N}$ ] with horizontal resolution of $0.25^{\circ}$ and $50 \sigma$-layers (Table 2). The bottom topography is derived from ETOPO1, a 1 arc-minute global relief model of Earth's surface (Amante and Eakins, 2009). We apply a Gaussian filter with $e$-folding scales of $200 \mathrm{~km}$ to the topography to reduce the pressure gradient errors in sigma coordinate models caused by steep bottom

185 slopes (Mellor et al., 1994) and fulfill the condition $\left|H_{i+1}-H_{i}\right| /\left|H_{i+1}+H_{i}\right|<0.2$, where $H_{i}$ and $H_{i+1}$ are bottom topographies at adjacent grids. Monthly (Seasonal) temperature and salinity climatologies from World Ocean Atlas 2018 (WOA18; Locarnini et al., 2019; Zweng et al., 2019) with horizontal resolution of $1^{\circ}$ and 57 (102) layers are used for an initial condition over depths shallower (deeper) than $1500 \mathrm{~m}$. Lateral boundary conditions for temperature, salinity, and horizontal velocity are obtained from Simple Ocean Data Assimilation (SODA; Carton et al. 2018) version 3.7.2 with

190 horizontal resolution of $0.5^{\circ}$ and 50 layers. Here, to satisfy volume conservation, flow relaxation (Guo et al., 2003) is applied to the horizontal velocity at the lateral boundary. The Japanese 55-year Reanalysis (JRA55; Kobayashi et al. 2015) with horizontal and temporal resolution of $1.25^{\circ}$ and 6 hours, respectively, is adopted for the atmospheric boundary conditions including air temperature and specific humidity at $2 \mathrm{~m}$, wind velocity at $10 \mathrm{~m}$, shortwave radiation, total cloud fraction, sea level pressure, and precipitation. We also use river discharge from the Japan Aerospace Exploration Agency (JAXA)'s land

195 surface and river simulation system, Today's Earth (TE)-Global (https://www.eorc.jaxa.jp/water/), with horizontal and temporal resolution of $0.25^{\circ}$ and 3 hours, respectively. The atmospheric and lateral boundary conditions are perturbed as described in Sect. 2.2, except for the rainfall and river discharge.

The model is driven by wind stresses and heat and freshwater fluxes using bulk formulae in which bulk coefficients are estimated from the Coupled Ocean-Atmosphere Response Experiment (COARE) version 3.5 bulk algorithm (Brodeau et al., 2017; Edson et al., 2013). The horizontal diffusivity coefficient is calculated by a Smagorinsky type formulation with a coefficient of 0.1 (Smagorinsky et al., 1965) and is assumed to be one-fifth of the horizontal viscosity coefficient. The vertical diffusivity coefficient is estimated by the Level 2.5 version of Nakanishi and Niino (2009). The model is spun up from 1 January 2011 to 6 July 2015 using the initial condition with no motion. During the spin-up period, simulated temperatures and salinity are nudged towards the monthly climatologies from WOA18 with a 90-day timescale to damp 
northward overshooting of the Kuroshio. We have confirmed that the perturbed boundary conditions substantially increase the ensemble spread even with the nudging (figure not shown).

\subsection{Data assimilation}

We implement the three-dimensional local ensemble transform Kalman filter (3D-LETKF; Hunt et al. 2007; Miyoshi and 210 Yamane 2007) with 100 ensemble members to assimilate the following observations on a 1 day assimilation interval (Table 3): satellite SSTs from Himawari-8 and GCOM-W, SSS from the SMOS (http://www.esa.int/Applications/Observing_the_Earth/SMOS) and Soil Moisture Active Passive (SMAP) version 4.3 (Meissner et al., 2018), SSH consisting of satellite SSH anomalies from the Copernicus Marine Environment Monitoring Service (CMEMS; http://marine.copernicus.eu/) and mean dynamic ocean topography estimated from simulated SSH 215 averaged in 2012-14, and in-situ temperature and salinity from the Global Temperature and Salinity Profile Programme (GTSPP; Sun et al., 2010) and Advanced automatic QC (AQC) Argo Data version 1.2a (http://www.jamstec.go.jp/ARGO/argo_web/argo/?page_id=100\&lang=en). We exclude satellite SSS within $100 \mathrm{~km}$ of the coasts, SSH for bottom topography shallower than $200 \mathrm{~m}$, in-situ temperature and salinity duplicated between the GTSPP and AQC Argo, and observations without the best quality flags or whose differences from the forecasts are larger than the

220 values in the growth error check in Table 3. Following Miyazawa et al. (2012) and Penny et al. (2013), the localization scales based on a Gaussian function are chosen to be $300 \mathrm{~km}$ and $100 \mathrm{~m}$ in the horizontal and vertical directions, respectively. An observational error covariance matrix is assumed to be diagonal using the observation errors in Table 3 .

\subsection{Sensitivity experiments}

225 We conduct sensitivity experiments with combining the IAU and covariance inflation methods [No inflation (NO INFL), RTPP, RTPS, and MULT] to investigate their impacts on the geostrophic balance and accuracy. We set the relaxation parameters in the RTPP and RTPS experiments to $\alpha_{R T P P}=\alpha_{R T P S}=0.9$ without the IAU and $\alpha_{R T P P}=\alpha_{R T P S}=$ $0.5,0.6, \ldots, 1.2$ with the IAU, and the inflation parameter to $\rho=1.05^{2}$ (inflating the forecast ensemble spread by $5 \%$ ) in the MULT experiments, regardless of the application of the IAU. In this study, we do not explore all values of the relaxation and 230 inflation parameters because of the limitations of computational resources. Hereafter, we refer to the RTPP experiments implemented with and without the IAU as the RTPP+IAU and RTPP experiments, respectively, and the RTPP+IAU experiment with a relaxation parameter of 0.5 as the RTPP05+IAU experiment. Kotsuki et al. (2017) indicated that the RTPP and RTPS do not consider the model error explicitly and that the optimal relaxation parameter may be larger than 1.0. 
Therefore, we perform experiments with the relaxation parameter $>1$. To clarify the effects of the IAU and covariance

inflation methods, the NO INFL experiment is defined as a control experiment in this study [See Eqs. (9) and (10)].

We integrate the LETKF-based ocean data assimilation system from 7 July 2015 at the start date of the Himawari-8 observations to 31 December 2016, applying the SSS nudging with 90-day timescale to damp a surface freshening drift. We estimate $\triangle N B E$ from ensemble analysis increments on days 1 and 16 of each month, the RMSDs from the daily averaged ensemble mean, and the ensemble spread from the daily-mean ensemble. The results in the RTPP11+IAU and RTPP12+IAU experiments are not shown because numerical instability developed.

\section{Results}

\subsection{Geostrophic balance}

We first compare the geostrophic balance for the various sensitivity experiments using spatiotemporally averaged $\triangle N B E$ over the whole system domain for 2016 (Fig. 1). The NO INFL+IAU experiment has the best geostrophic balance with significant improvement relative to the NO INFL experiment, and thus the IAU plays a role in enhancing the balance. In contrast, since the RTPP09 and RTPS09 experiments show significantly larger $\triangle N B E$ than the NO INFL experiment, the RTPP and RTPS contribute to breaking the balance. The MULT+IAU and MULT experiments give such large $\triangle N B E$ of 2.11 and $5.22 \times 10^{-10} \mathrm{~s}^{-2}$, respectively, that the MULT breaks the balance considerably even if the IAU is applied.

The RTPP+IAU and RTPS+IAU experiments provide significant improvement when the relaxation parameters are $\alpha_{R T P P} \leq 0.9$ and $\alpha_{R T P S} \leq 0.8$, respectively. The RTPP11+IAU experiment becomes numerically unstable in December 2015 and the RTPS11+IAU experiment also significantly degrades the balance, and thus relaxation parameters larger than 1.0 do not appear to be appropriate for an EnKF-based ocean data assimilation system. The combinations of the IAU and RTPP/RTPS, in which the relaxation parameters are set to $\alpha_{R T P P} \leq 0.9$ and $\alpha_{R T P S} \leq 0.8$, appear to maintain geostrophic 255 balance.

To investigate spatial characteristics of the geostrophic balance, $\triangle N B E$ is temporally averaged over the whole year 2016 (Fig. 2). Here, the RTPP09+IAU and RTPS11+IAU experiments are shown from the RTPP+IAU and RTPS+IAU experiments, because they have the best accuracy as seen in Sect. 4.2. The NO INFL, RTPP09, and RTPS09 experiments produce less balanced fields in the mid-latitude region, especially around the KE (Fig. 2a, c, e). In the RTPS11+IAU experiment, the balance is also lost in higher latitude regions (Fig. 2f). In the MULT and MULT+IAU experiments, there are almost no balanced regions with $\triangle N B E$ smaller than $1.5 \times 10^{-10} \mathrm{~s}^{-2}$ (figure not shown). The NO INFL+IAU and RTPP09+IAU experiments show substantial improvement around the KE region, although the relatively large $\triangle N B E$ remains along the KE in the RTPP09+IAU experiment (Fig. 2b, d). Thus, in general, although the balance in the analysis 
field is not maintained around the KE region, this imbalance is substantially improved in the NO INFL+IAU and

RTPP09+IAU experiments.

\subsection{Accuracy}

\subsubsection{Surface flow field}

We evaluate the accuracy of the surface flow field in the sensitivity experiments, calculating the RMSDs relative to the

AVISO observational SSH and SSHA gridded datasets as well as surface zonal and meridional velocity from the drifter buoys. We also estimate the ensemble spread in observational space. As described in Sect. 2.4.3, the AVISO dataset is not independent because it uses satellite SSHAs assimilated in our system, whereas the drifter buoys are independent. The RMSDs and ensemble spreads are averaged over the whole domain for 2016 in the SSH and SSHA fields (Fig. 3) and the surface zonal and meridional velocity (Fig. 4). Compared with the NO INFL experiment, the NO INFL+IAU experiment has significantly larger RMSDs and smaller ensemble spreads in most of the variables, whereas the RTPP09 and RTPS09 experiments show significantly smaller RMSDs and larger spreads. This indicates that the IAU has a significant effect on reducing the accuracy in the surface flow field because the ensemble spread is relatively small, and that in contrast the RTPP and RTPS lead to significant improvement by inflating the ensemble spread. The MULT and MULT+IAU experiments yield poor accuracy and very large ensemble spreads in the flow fields; for example, the averaged SSH RMSDs of 0.22 and 0.24 $\mathrm{m}$ and the averaged SSH and SSHA ensemble spreads of 0.41 and $0.74 \mathrm{~m}$, respectively. Thus, the MULT does not have sufficient skill in reproducing the flow field.

In both RTPP+IAU and RTPS+IAU experiments, the ensemble spreads are increased in all of the variables for the larger relaxation parameters. In the RTPP+IAU experiments, the accuracy of SSH and SSHA is the highest for $\alpha_{R T P P}=0.8$, although there is no significant improvement relative to the NO INFL experiment. The accuracy in both zonal and meridional velocity improves with larger relaxation parameter, and significantly improves for $\alpha_{R T P P}=0.8-1.0$. Consequently, $\alpha_{R T P P}=0.8-0.9$ in the RTPP+IAU experiment may be appropriate to represent the flow field more accurately.

In the RTPS+IAU experiment, the accuracy of the SSH, SSHA, and horizontal velocity tends to improve as the relaxation parameter increases, and then significant degradation suddenly occurs for $\alpha_{R T P S}=1.2$. For $\alpha_{R T P S}=1.1$, the RTPS+IAU experiment has the best accuracy for SSH and SSHA but significant improvement only in SSHA. For $\alpha_{R T P S}=$ 1.0, the accuracy in both zonal and meridional velocity is significantly higher. Therefore, $\alpha_{R T P S}=1.0-1.1$ seems to be the best among the RTPS+IAU experiments. We note that the accuracy of the SSH and SSHA in the RTPP+IAU and RTPS+IAU experiments does not surpass the RTPP09 and RTPS09 experiments, probably because the IAU method does not 
use the SSH analyses. Furthermore, the comparison between the RTPP+IAU and RTPS+IAU experiments suggests that the combination of the IAU and RTPP has higher skill in reproducing the flow field.

To examine spatial features of the accuracy and ensemble spread, the RMSDs and ensemble spreads in the SSHA are also averaged over 2016 (Figs. 5 and 6, respectively). In most experiments, large RMSDs and ensemble spreads are distributed around the KE region where there are abundant fronts and eddies. Compared with the NO INFL experiment, the ensemble spreads become smaller in the mid-latitude region in the NO INFL+IAU experiment, and thus the accuracy around the KE region is degraded. The RTPP09, RTPS09, RTPP09+IAU, and RTPS11+IAU experiments show larger ensemble spreads leading to improvement of the accuracy around the KE region. However, the larger ensemble spread is also seen in the subtropical region in the RTPS11+IAU experiment. This does not seem reasonable because a free ensemble experiment does not demonstrate such spread even if the perturbed atmospheric and lateral boundary conditions are applied (figure not shown).

\subsubsection{The KEO buoy}

We also calculate the RMSDs relative to independent observations of temperature, salinity, and horizontal velocity from the KEO buoy located south of the KE (Fig. 5a). Here, only the temperature and salinity results are shown, as there is almost no significant improvement and even degradation in the horizontal velocity. There is hardly any difference between the NO INFL+IAU and NO INFL experiments in the temperature accuracy, whereas the salinity accuracy is significantly degraded around 0-200 m depth in the NO INFL experiment (Fig. 7). Thus, the IAU may reduce the accuracy, although this is not as obvious as for the flow field shown in Sect. 4.2.1. The RTPP and RTPS experiments give significantly better accuracy than the NO INFL experiment in both temperature and salinity, and thus the RTPP and RTPS play a role in enhancing the accuracy.

When the relaxation parameter is $\alpha_{R T P P}=0.7-1.0$ in the RTPP+IAU experiment, the temperature accuracy is significantly enhanced around $200-500 \mathrm{~m}$ depth, although there is a slight degradation around $50-150 \mathrm{~m}$ depth (Fig. 8a). For the parameter values in that range, the salinity accuracy is also significantly improved in almost all depths (Fig. 8c). Since the temperature accuracy is the best at $\alpha_{R T P P}=0.8-0.9$ and salinity accuracy improves as the relaxation parameter increases, the appropriate relaxation parameter would be $\alpha_{R T P P}=0.8-0.9$ in the RTPP+IAU experiment.

In the RTPS+IAU experiments, the temperature accuracy below $200 \mathrm{~m}$ depth is significantly improved for $\alpha_{R T P S}=$ $0.8-1.1$, whereas that above $200 \mathrm{~m}$ depth is significantly degraded for $\alpha_{R T P S}=0.5-0.8$ and $\alpha_{R T P S}=1.2$. The salinity accuracy improves over almost the whole depth when the relaxation parameter is $\alpha_{R T P S}=1.0-1.2$, whereas there is significant degradation around 0-200 m depth when the relaxation parameter is $\alpha_{R T P S}=0.5-0.9$. Therefore, the suitable 
relaxation parameter is $\alpha_{R T P S}=1.0-1.1$ in the RTPS+IAU experiment. As shown in Fig. 7, both RTPP09+IAU and

RTPS11+IAU experiments have higher accuracy than the NO INFL, NO INFL+IAU, RTPP09, and RTPS09 experiments.

\section{Summary}

In this study, we have developed an EnKF-based ocean data assimilation system with an assimilation interval of 1 day to take advantage of frequent satellite observations, and we have conducted sensitivity experiments to explore the best combination of the IAU and covariance inflation methods by evaluating the geostrophic balance and accuracy. Table 4 summarizes the overall evaluation in this study. The IAU and RTPP/RTPS have opposite effects to each other; namely, the IAU improves the balance but degrades the accuracy, reducing the ensemble spread, whereas the RTPP and RTPS degrade balance and improve accuracy by inflating the ensemble spread. The RTPP+IAU experiment provides significantly better balance for the relaxation parameters of $\alpha_{R T P P} \leq 0.9$ as well as better accuracy when the relaxation parameter is $\alpha_{R T P P}=$ $3350.8-1.0$. Therefore, this study demonstrates that the appropriate parameter is $\alpha_{R T P P}=0.8-0.9$ when the IAU and RTPP are combined. In contrast, the RTPS+IAU experiment does not significantly improve balance and accuracy at the same time, because the balance is significantly better for a relaxation parameter of $\alpha_{R T P S} \leq 0.8$, and the accuracy is significantly higher when the relaxation parameter is $\alpha_{\text {RTPS }}=1.0-1.1$. Therefore, this study demonstrates that the combination of the IAU and RTPP with the relaxation parameter of $\alpha_{R T P P}=0.8-0.9$ is the most suitable for the EnKF-based ocean data assimilation 340 system.

The MULT with a 5\% inflation of the forecast ensemble spread does not have sufficient skill in maintaining the balance and accurately reproducing the flow field, regardless of whether or not the IAU is applied. It might be possible that MULT produce analyses with good balance and accuracy by tuning the inflation parameter. However, since the computational cost of tuning the parameters in all covariance inflation methods is high, this study focuses on the combination of the RTPP/RTPS and IAU with good balance and accuracy. This system still contains other tuning parameters in the perturbed atmospheric forcing, ensemble size, localization scale, and observation errors. Further experiments are required to determine the best settings for a given computational resource, and we will address this issue in future studies.

The results of this study would also be useful for constructing EnKF-based data assimilation systems in other fields in which gravity waves have substantial impacts. Furthermore, this study may help improve the accuracy of existing EnKFbased data assimilation systems. Table 1 shows that there are no eddy-resolving EnKF-based ocean reanalysis datasets in the Pacific region. We are now planning to construct such analysis datasets and real-time ensemble prediction systems.

\section{Code and data availability}


The source codes of the sbPOM and LETKF are available from https://github.com/shunohishi/sbPOM-LETKF (last access: 2 March 2022, Jordi and Wang, 2012) and https:/github.com/takemasa-miyoshi/letkf (last access: 13 April 2021, Miyoshi and Yamane, 2007), respectively. The source code of the COARE version 3.5 is downloaded from https://github.com/brodeau/aerobulk (last access: 13 April 2021, Brodeau et al., 2017; Edson et al., 2013).

We thank Dr. Kenshi Hibino for providing us with the earlier version of the TE-Global before the official release of the latest version (https://www.eorc.jaxa.jp/water/, last access: 13 April 2021). Details of the observational datasets are as follows: the surface drifter buoys from https:/www.aoml.noaa.gov/phod/gdp/hourly data.php (last access: 13 April 2021, Elipot et al., 2016); the KEO buoy from https://www.pmel.noaa.gov/ocs/ (last access: 13 April 2021); the ETOPO1 from https://www.ngdc.noaa.gov/mgg/global/ (last access: 13 April 2021, Amante and Eakins, 2009); the WOA18 https://www.ncei.noaa.gov/access/world-ocean-atlas-2018/ (last access: 13 April 2021; Locarnini et al., 2019; Zweng et al., 2019); the Himawari-8 satellite SSTs from https://www.eorc.jaxa.jp/ptree/index.html (last access: 13 April 2021; Bessho et al., 2016; Kurihara et al., 2016); the GCOM-W SSTs from https://gportal.jaxa.jp/gpr/?lang=en (last access: 13 April 2021); the satellite SSS from SMOS at http://www.esa.int/Applications/Observing the Earth/SMOS (last access: 13 April 2021) and SMAP version 4.3 from https://podaac.jpl.nasa.gov/ (last access: 13 April 2021, Meissner et al., 2018); the satellite SSHA and AVISO (Ducet et al., 2000) from the CMEMS (https://marine.copernicus.eu/, last access: 13 April 2021); and insitu temperature and salinity from the GTSPP (https:/www.ncei.noaa.gov/products/global-temperature-and-salinity-profileprogramme, last access: 13 April 2021, Sun et al., 2010) and AQC Argo version 1.2a (http://www.jamstec.go.jp/ARGO/argo_web/argo/?page id=100\&lang=en, last access: 13 April 2021). The global JRA55 atmosphere and SODA 3.7.2 ocean reanalysis datasets are from http://search.diasjp.net/en/dataset/JRA55 (last access: 13 April 2021, Kobayashi et al., 2015) and https://www.soda.umd.edu/soda3 readme.htm (last access: 13 April 2021, Carton et al., 2018), respectively.

\section{Author contributions}

SO, TH, and YM developed the code of the ocean data assimilation system. SO conducted the sensitivity experiments and analyzed their outputs. SO and TM prepared the paper with contributions from all coauthors (TH, HA, JI, YM, and MK).

\section{Competing interests}

The authors declare that they have no conflict of interest.

\section{Acknowledgments}


We are very grateful to Dr. Shunji Kotsuki at Chiba University for providing us with sample code of the RTPP and RTPS. Numerous comments from Drs. Nariaki Hirose, Takahiro Toyoda, Yosuke Fujii, and Norihisa Usui at the Meteorological Research Institute, Yoichi Ishikawa at JAMSTEC, Katsumi Takayama at IDEA Consultants, Inc., Naoki Hirose at Kyushu University, and participants in the ocean data assimilation summer school also helped us develop the system. This work used computational resources of the JAXA Supercomputer System Generation 2 and 3 (JSS2 and JSS3, respectively) and the supercomputer Fugaku provided by RIKEN through the HPCI Research Project (Project ID: hp210166, ra000007).

\section{Financial support}

This work was supported by JST AIP Grant Number JPMJCR19U2, Japan; MEXT (JPMXP1020200305) as "Program for Promoting Researches on the Supercomputer Fugaku" (Large Ensemble Atmospheric and Environmental Prediction for Disaster Prevention and Mitigation); the COE research grant in computational science from Hyogo Prefecture and Kobe City through Foundation for Computational Science; JST, SICORP Grant Number JPMJSC1804, Japan; JSPS KAKENHI Grant Number JP19H05605; the JAXA; JST, CREST Grant Number JPMJCR20F2, Japan; Cabinet Office, Government of Japan, Cross-ministerial Moonshot Agriculture, Forestry and Fisheries Research and Development Program, "Technologies for Smart Bio-industry and Agriculture"(funding agency: Bio-oriented Technology Research Advancement Institution) No. JPJ009237; RIKEN Pioneering Project "Prediction for Science"; RIKEN Engineering Network Project.

\section{Review statement}

\section{References}

Amante, C. and Eakins, B. W.: ETOPO1 1 Arc-Minute Global Relief Model: Procedures, Data Sources and Analysis., 2009.

405 Anderson, J. L.: An ensemble adjustment Kalman filter for data assimilation, Mon. Weather Rev., 129(12), 2884-2903, doi:10.1175/1520-0493(2001)129<2884:AEAKFF>2.0.CO;2, 2001.

Baduru, B., Paul, B., Banerjee, D. S., Sanikommu, S. and Paul, A.: Ensemble based regional ocean data assimilation system for the Indian Ocean: Implementation and evaluation, Ocean Model., 143(September), 101470, doi:10.1016/j.ocemod.2019.101470, 2019.

410 Balmaseda, M. A., Hernandez, F., Storto, A., Palmer, M. D., Alves, O., Shi, L., Smith, G. C., Toyoda, T., Valdivieso, M., Barnier, B., Behringer, D., Boyer, T., Chang, Y. S., Chepurin, G. A., Ferry, N., Forget, G., Fujii, Y., Good, S., Guinehut, S., Haines, K., Ishikawa, Y., Keeley, S., Köhl, A., Lee, T., Martin, M. J., Masina, S., Masuda, S., Meyssignac, B., Mogensen, K., Parent, L., Peterson, K. A., Tang, Y. M., Yin, Y., Vernieres, G., Wang, X., Waters, J., Wedd, R., Wang, O., Xue, Y., 
https://doi.org/10.5194/gmd-2022-40

Preprint. Discussion started: 4 March 2022

(c) Author(s) 2022. CC BY 4.0 License.

(c) (i)

Chevallier, M., Lemieux, J. F., Dupont, F., Kuragano, T., Kamachi, M., Awaji, T., Caltabiano, A., Wilmer-Becker, K. and

Gaillard, F.: The ocean reanalyses intercomparison project (ORA-IP), J. Oper. Oceanogr., 8(0), s80-s97, doi:10.1080/1755876X.2015.1022329, 2015.

Bessho, K., Date, K., Hayashi, M., Ikeda, A., Imai, T., Inoue, H., Kumagai, Y., Miyakawa, T., Murata, H., Ohno, T., Okuyama, A., Oyama, R., Sasaki, Y., Shimazu, Y., Shimoji, K., Sumida, Y., Suzuki, M., Taniguchi, H., Tsuchiyama, H., Uesawa, D., Yokota, H. and Yoshida, R.: An Introduction to Himawari-8/9 - Japan's new-generation geostationary meteorological satellites, J. Meteorol. Soc. Japan, 94(2), 151-183, doi:10.2151/jmsj.2016-009, 2016.

Bloom, S. C., Takacs, L. L., da Silva, A. M. and Ledvina, D.: Data assimilation using incremental analysis updates, Mon. Weather Rev., 124(6), 1256-1271, doi:10.1175/1520-0493(1996)124<1256:DAUIAU>2.0.CO;2, 1996.

Brodeau, L., Barnier, B., Gulev, S. K. and Woods, C.: Climatologically significant effects of some approximations in the bulk parameterizations of turbulent air-sea fluxes, J. Phys. Oceanogr., 47(1), 5-28, doi:10.1175/JPO-D-16-0169.1, 2017.

425 Carton, J. A., Chepurin, G. A. and Chen, L.: SODA3: A new ocean climate reanalysis, J. Clim., 31(17), 6967-6983, doi:10.1175/JCLI-D-17-0149.1, 2018.

Chakraborty, A., Sharma, R., Kumar, R. and Basu, S.: A SEEK filter assimilation of sea surface salinity from Aquarius in an OGCM: Implication for surface dynamics and thermohaline structure, J. Geophys. Res. Ocean., 119, 4777-4796, doi:10.1002/2014JC009984, 2014.

430 Ducet, N., Le Traon, P. Y. and Reverdin, G.: Global high-resolution mapping of ocean circulation from TOPEX/Poseidon and ERS-1 and -2, J. Geophys. Res., 105(C8), 19477-19498, doi:10.1029/2000JC900063, 2000.

Edson, J. B., Jampana, V., Weller, R. A., Bigorre, S. P., Plueddemann, A. J., Fairall, C. W., Miller, S. D., Mahrt, L., Vickers, D. and Hersbach, H.: On the exchange of momentum over the open ocean, J. Phys. Oceanogr., 43(8), 1589-1610, doi:10.1175/JPO-D-12-0173.1, 2013.

435 Elipot, S., Lumpkin, R., Perez, R. C., Lilly, J. M., Early, J. J. and Sykulski, A. M.: A global surface drifter data set at hourly resolution, J. Geophys. Res. Ocean., 121(5), 2937-2966, doi:10.1002/2016JC011716, 2016.

Evensen, G.: Sequential data assimilation with a nonlinear quasi-geostrophic model using Monte Carlo methods to forecast error statistics, J. Geophys. Res., 99, 10143-10162, 1994.

Evensen, G.: The Ensemble Kalman Filter: Theoretical formulation and practical implementation, Ocean Dyn., 53, 343-367,

440 doi:10.1007/s10236-003-0036-9, 2003.

Guo, X., Hukuda, H., Miyazawa, Y. and Yamagata, T.: A triply nested ocean model for simulating the Kuroshio-Roles of horizontal resolution on JEBAR, J. Phys. Oceanogr., 33(1), 146-169, doi:10.1175/1520-

0485(2003)033<0146:ATNOMF>2.0.CO;2, 2003. 
https://doi.org/10.5194/gmd-2022-40

Preprint. Discussion started: 4 March 2022

(c) Author(s) 2022. CC BY 4.0 License.

(c) (i)

Hackert, E., Busalacchi, A. J. and Ballabrera-Poy, J.: Impact of Aquarius sea surface salinity observations on coupled

forecasts for the tropical Indo-Pacific Ocean, J. Geophys. Res. Ocean., 119, 4045-4067, doi:10.1002/2013JC009697, 2014.

He, H., Lei, L., Whitaker, J. S. and Tan, Z. M.: Impacts of assimilation frequency on ensemble Kalman filter data assimilation and imbalances, J. Adv. Model. Earth Syst., 12(10), doi:10.1029/2020MS002187, 2020.

Houtekamer, P. L. and Zhang, F.: Review of the ensemble Kalman filter for atmospheric data assimilation, Mon. Weather Rev., 144(12), 4489-4532, doi:10.1175/MWR-D-15-0440.1, 2016.

Hunt, B. R., Kostelich, E. J. and Szunyogh, I.: Efficient data assimilation for spatiotemporal chaos: A local ensemble transform Kalman filter, Phys. D, 230, 112-126, doi:10.1016/j.physd.2006.11.008, 2007.

Jordi, A. and Wang, D. P.: sbPOM: A parallel implementation of Princenton Ocean Model, Environ. Model. Softw., 38, 5961, doi:10.1016/j.envsoft.2012.05.013, 2012.

Karspeck, A. R., Yeager, S., Danabasoglu, G., Hoar, T., Collins, N., Raeder, K., Anderson, J. and Tribbia, J.: An ensemble adjustment kalman filter for the CCSM4 ocean component, J. Clim., 26(19), 7392-7413, doi:10.1175/JCLI-D-12-00402.1, 2013.

Kobayashi, S., Ota, Y., Harada, Y., Ebita, A., Moriya, M., Onoda, H., Onogi, K., Kamahori, H., Kobayashi, C., Endo, H., Miyaoka, K. and Takahashi, K.: The JRA-55 reanalysis: General specifications and basic characteristics, J. Meteorol. Soc. Japan, 93(1), 5-48, doi:10.2151/jmsj.2015-001, 2015.

460 Kotsuki, S., Ota, Y. and Miyoshi, T.: Adaptive covariance relaxation methods for ensemble data assimilation: experiments in the real atmosphere, Q. J. R. Meteorol. Soc., 143(705), 2001-2015, doi:10.1002/qj.3060, 2017.

Kunii, M. and Miyoshi, T.: Including uncertainties of sea surface temperature in an ensemble Kalman filter: A case study of typhoon Sinlaku (2008), Weather Forecast., 27(6), 1586-1597, doi:10.1175/WAF-D-11-00136.1, 2012.

Kurihara, Y., Murakami, H. and Kachi, M.: Sea surface temperature from the new Japanese geostationary meteorological 465 Himawari-8 satellite, Geophys. Res. Lett., 43(3), 1234-1240, doi:10.1002/2015GL067159, 2016.

Locarnini, R. A., Mishonov, A. V., Baranova, O. K., Boyer, T. P., Zweng, M. M., Garcia, H. E., Reagan, J. R., Seidov, D., Weathers, K. W., Paver, C. R. and Smolyar, I. V.: World Ocean Atlas 2018, Volume 1: Temperature. A. Mishonov, Technical Editor., NOAA Atlas NESDIS, 81(July), 52, 2019.

Martin, M. J., Balmaseda, M., Bertino, L., Brasseur, P., Brassington, G., Cummings, J., Fujii, Y., Lea, D. J., Lellouche, J. M., 470 Mogensen, K., Oke, P. R., Smith, G. C., Testut, C. E., Waagbø, G. A., Waters, J. and Weaver, A. T.: Status and future of data assimilation in operational oceanography, J. Oper. Oceanogr., 8(0), s28-s48, doi:10.1080/1755876X.2015.1022055, 2015. 
https://doi.org/10.5194/gmd-2022-40

Preprint. Discussion started: 4 March 2022

(c) Author(s) 2022. CC BY 4.0 License.

(c) (i)

Meissner, T., Wentz, F. J. and Vine, D. M. Le: The Salinity Retrieval Algorithms for the NASA Aquarius Version 5 and SMAP Version 3 Releases, Remote Sens., 10(7), 1121, doi:10.3390/rs10071121, 2018.

Mellor, G. L., Ezer, T. and Oey, L.-Y.: The pressure gradient conundrum of sigma coordinate ocean models, J. Atmos. Ocean. Technol., 11(4), 1126-1134, doi:10.1175/1520-0426(1994)011<1126:TPGCOS>2.0.CO;2, 1994.

Miyazawa, Y., Miyama, T., Varlamov, S. M., Guo, X. and Waseda, T.: Open and coastal seas interactions south of Japan represented by an ensemble Kalman filter, Ocean Dyn., 62(4), 645-659, doi:10.1007/s10236-011-0516-2, 2012.

Miyoshi, T.: The gaussian approach to adaptive covariance inflation and its implementation with the local ensemble transform Kalman filter, Mon. Weather Rev., 139(5), 1519-1535, doi:10.1175/2010MWR3570.1, 2011.

Miyoshi, T. and Yamane, S.: Local Ensemble Transform Kalman Filtering with an AGCM at a T159/L48 Resolution, Mon. Weather Rev., 135(11), 3841-3861, doi:10.1175/2007MWR1873.1, 2007.

Nakanishi, M. and Niino, H.: Development of an improved turbulence closure model for the atmospheric boundary layer, J. Meteorol. Soc. Japan, 87(5), 895-912, doi:10.2151/jmsj.87.895, 2009.

Penny, S. G., Kalnay, E., Carton, J. A., Hunt, B. R., Ide, K., Miyoshi, T. and Chepurin, G. A.: The local ensemble transform Kalman filter and the running-in-place algorithm applied to a global ocean general circulation model, Nonlinear Process. Geophys., 20(6), 1031-1046, doi:10.5194/npg-20-1031-2013, 2013.

Penny, S. G., Behringer, D. W., Carton, J. A. and Kalnay, E.: A hybrid global ocean data assimilation system at NCEP, Mon. Weather Rev., 143(11), 4660-4677, doi:10.1175/MWR-D-14-00376.1, 2015.

490 Sakov, P. and Oke, P. R.: A deterministic formulation of the ensemble Kalman filter: An alternative to ensemble square root filters, Tellus, Ser. A Dyn. Meteorol. Oceanogr., 60 A(2), 361-371, doi:10.1111/j.1600-0870.2007.00299.x, 2008. Sakov, P., Counillon, F., Bertino, L., Lisæter, K. A., Oke, P. R. and Korablev, A.: TOPAZ4: an ocean-sea ice data assimilation system for the North Atlantic and Arctic, Ocean Sci., 8(4), 633-656, doi:10.5194/os-8-633-2012, 2012.

Shibuya, R., Sato, K., Tomikawa, Y., Tsutsumi, M. and Sato, T.: A study of multiple tropopause structures caused by inertiagravity waves in the antarctic, J. Atmos. Sci., 72(5), 2109-2130, doi:10.1175/JAS-D-14-0228.1, 2015.

Smagorinsky, J., Manabe, S. and Holloway, J. L.: Numerical results from a nine-level general circulation model of the atmosphere, Mon. Weather Rev., 93, 727-768, doi:10.1175/1520-0493(1965)093<0727:NRFANL>2.3.CO;2, 1965. Sun, C., Thresher, A., Keeley, R., Hall, N., Hamilton, M., Chinn, P., A.Tran, Goni, G., Villeon, L. P. de la, Carval, T., Cowen, L., Manzella, G., Gopalakrishna, V., Guerrero, R., Reseghetti, F., Kanno, Y., Klein, B., Rickard, L., Baldoni, A., Lin, 500 S., Ji, F. and Nagaya, Y.: The data management system for the global temperature and salinity profile programme, in Proceedings of OceanObs'09: Sustained Ocean Observations and Information for Society, pp. 931-938, European Space Agency., 2010. 
https://doi.org/10.5194/gmd-2022-40

Preprint. Discussion started: 4 March 2022

(c) Author(s) 2022. CC BY 4.0 License.

(c) (i)

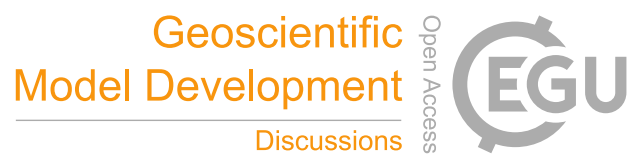

Torn, R. D., Hakim, G. J. and Snyder, C.: Boundary conditions for limited-area ensemble Kalman filters, Mon. Weather Rev., 134(9), 2490-2502, doi:10.1175/MWR3187.1, 2006.

505 Toyoda, T., Fujii, Y., Kuragano, T., Matthews, J. P., Abe, H., Ebuchi, N., Usui, N., Ogawa, K. and Kamachi, M.:

Improvements to a global ocean data assimilation system through the incorporation of Aquarius surface salinity data, Q. J. R. Meteorol. Soc., 141(692), 2750-2759, doi:10.1002/qj.2561, 2015.

Whitaker, J. S. and Hamill, T. M.: Evaluating methods to account for system errors in ensemble data assimilation, Mon.

Weather Rev., 140(9), 3078-3089, doi:10.1175/MWR-D-11-00276.1, 2012.

510 Yin, Y., Alves, O. and Oke, P. R.: An ensemble ocean data assimilation system for seasonal prediction, Mon. Weather Rev., 139(3), 786-808, doi:10.1175/2010MWR3419.1, 2011.

Ying, Y. and Zhang, F.: An adaptive covariance relaxation method for ensemble data assimilation, Q. J. R. Meteorol. Soc., 141(692), 2898-2906, doi:10.1002/qj.2576, 2015.

Zhang, F., Davis, C. A., Kaplan, M. L. and Koch, S. E.: Wavelet analysis and the governing dynamics of a large-amplitude

515 mesoscale gravity-wave event along the east coast of the United States, Q. J. R. Meteorol. Soc., 127(577), 2209-2245, doi:10.1002/qj.49712757702, 2001.

Zhang, F., Snyder, C. and Sun, J.: Impacts of initial estimate and observation availability on convective-scale data assimilation with an ensemble Kalman filter, Mon. Weather Rev., 132(5), 1238-1253, doi:10.1175/1520-

0493(2004)132<1238:IOIEAO>2.0.CO;2, 2004.

520 Zweng, M. M., Reagan, J. R., Seidov, D., Boyer, T. P., Antonov, J. I., Locarnini, R. A., Garcia, H. E., Mishonov, A. V., Baranova, O. K., Weathers, K. W., Paver, C. R. and Smolyar, I. V.: World Ocean Atlas 2018, Volume 2: Salinity. A. Mishonov, Technical Editor, NOAA Atlas NESDIS, 82(July), 50, 2019. 
Table 1: Overview of EnKF-based ocean data assimilation systems developed after 2010. Abbreviations are PEODAS: Predictive Ocean Atmosphere Model for Australia (PAOMA) Ensemble Ocean Data Assimilation system; DEnKF: Deterministic EnKF (Sakov and Oke, 2008); LETKF: Local ensemble transform Kalman filter (Hunt et al., 2007); EAKF: Ensemble adjustment Kalman filter (Anderson, 2001); T: Temperature, S: Salinity, SST: Sea surface temperature, SSH: Sea surface height, and MULT: Multiplicative inflation. Adaptive MULT was proposed by Miyoshi (2011). Dashes are used to indicate no application. "Inflated obs. error" in TOPAZ4 indicates that observation errors are inflated when ensemble analyses are calculated.

\begin{tabular}{|c|c|c|c|c|c|c|c|}
\hline Name & $\begin{array}{c}\text { PEODAS } \\
\text { (Yin et al., 2011) }\end{array}$ & $\begin{array}{c}\text { TOPAZ4 } \\
\text { (Sakov et al., 2012) }\end{array}$ & $\begin{array}{c}\text { Miyazawa et al. } \\
\text { (2012) }\end{array}$ & $\begin{array}{c}\text { Karspeck et al. } \\
\text { (2013) }\end{array}$ & $\begin{array}{l}\text { Penny et al. } \\
\text { (2013) }\end{array}$ & $\begin{array}{l}\text { Penny et al. } \\
\text { (2015) }\end{array}$ & $\begin{array}{l}\text { Baduru et al. } \\
\text { (2019) }\end{array}$ \\
\hline Domain & Global & $\begin{array}{l}\text { North Atlantic } \\
+ \text { Arctic (Release) }\end{array}$ & South of Japan & Global & Quasi global & Global & Indian Ocean \\
\hline $\begin{array}{l}\text { Horizontal resolution } \\
\text { (longitude } \times \text { latitude) }\end{array}$ & $2^{\circ} \times 0.5-1.5^{\circ}$ & $\begin{array}{c}12-16 \mathrm{~km} \times \\
12-16 \mathrm{~km}\end{array}$ & $1 / 36^{\circ} \times 1 / 36^{\circ}$ & $1^{\circ} \times 1^{\circ}$ & $1^{\circ} \times 0.58-1^{\circ}$ & $\begin{array}{c}0.5^{\circ} \times \\
0.25-0.5^{\circ}\end{array}$ & $1 / 12^{\circ} \times 1 / 12^{\circ}$ \\
\hline Vertical resolution & 25 z-levels & 28 hybrid layers & 31 б-layers & 60 z-levels & 20 z-levels & 40 z-levels & $40 \sigma$-layers \\
\hline $\begin{array}{l}\text { Perturbed boundary } \\
\text { condition }\end{array}$ & Atmosphere & Atmosphere & - & - & Atmosphere & Atmosphere & Atmosphere \\
\hline EnKF & Simplified EnKF & DEnKF & LETKF & EAKF & LETKF & LETKF & LETKF \\
\hline Ensemble size & 11 & 100 & 20 & 48 & 40 & 28 & 80 \\
\hline Assimilation window & 5 days & 7 days & 2 days & 1 day & 5 days & 5 days & 5 days \\
\hline Assimilated data & $\mathrm{T}, \mathrm{S}$ & SST, SSH, T, S, Ice & $\mathrm{SST}, \mathrm{SSH}, \mathrm{T}, \mathrm{S}$ & $\mathrm{T}, \mathrm{S}$ & $\mathrm{T}, \mathrm{S}$ & $\mathrm{T}, \mathrm{S}$ & $\mathrm{SST}, \mathrm{T}, \mathrm{S}$ \\
\hline Covariance inflation & Additive inflation & - & MULT & - & $\begin{array}{l}\text { Adaptive } \\
\text { MULT }\end{array}$ & - & MULT \\
\hline IAU/Nudging & - & - & - & - & - & - & - \\
\hline Period & 1979-2006 & 1991-2019 & $2010.02 .08-28$ & 1998-2005 & 1997-2003 & 1991-98 & $\begin{array}{c}2016.08- \\
2018.09 \\
\end{array}$ \\
\hline Other & & Inflated obs. error & & & & & \\
\hline
\end{tabular}


https://doi.org/10.5194/gmd-2022-40

Preprint. Discussion started: 4 March 2022

(c) Author(s) 2022. CC BY 4.0 License.

(c) (i)

Table 2: Overview of the regional ocean model in the ocean data assimilation system

\begin{tabular}{ll}
\hline Ocean model & sbPOM (Jordi and Wang, 2012) \\
\hline Model domain & Northwestern Pacific $\left[117^{\circ}-180^{\circ} \mathrm{E}, 15^{\circ}-50^{\circ} \mathrm{N}\right]$ \\
\hline Horizontal resolution & $0.25^{\circ} \times 0.25^{\circ}$ \\
\hline Vertical layer & 50 б-layers \\
\hline Initial conditions & WOA18 (Locarnini et al., 2019; Zweng et al., 2019) \\
\hline Atmospheric forcing & JRA55 (Kobayashi et al., 2015) \\
\hline River discharge & TE-Global (https://www.eorc.jaxa.jp/water/) \\
\hline Lateral boundary condition & SODA version 3.7.2 (Carton et al., 2018) \\
\hline Spin-up period & 2011.01.01-2015.07.06 \\
\hline
\end{tabular}


Table 3: Overview of data assimilation in the ocean data assimilation system

\begin{tabular}{ll}
\hline Assimilation method & LETKF (Hunt et al., 2007; Miyoshi and Yamane, 2007) \\
\hline Ensemble size & 100 \\
\hline Assimilation cycle & 1 day \\
\hline Observations & Himawari-8 (Bessho et al., 2016; Kurihara et al., 2016) \\
\multicolumn{1}{c}{ SST } & GCOM-W (http://www.ghrsst.org) \\
& SMOS (https://earth.esa.int) \\
SSS & SMAP (https://www.jpl.nasa.gov) \\
SSH & DUACS multimission satellite data (https://marine.copernicus.eu/) \\
$\quad$ - SSHA & Climatology of model outputs in a spin-up period (2012-14) \\
- MDOT & GTSPP (Sun et al., 2010) \\
& AQC Argo data version 1.2a \\
Temperature and Salinity & (http://www.jamstec.go.jp/ARGO/argo_web/argo/?page id=100\&lang=en) \\
\hline Horizontal localization scale & $300 \mathrm{~km}$ \\
\hline Vertical localization scale & $100 \mathrm{~m}$ \\
\hline Observation error & \\
SST & $1.5^{\circ} \mathrm{C}$ \\
SSS & 0.3 \\
SSH & $0.2 \mathrm{~m}$ \\
Temperature & $1.5^{\circ} \mathrm{C}$ \\
Salinity & 0.3 \\
\hline Growth error check & \pm 2 \\
SST & $\pm 5^{\circ} \mathrm{C}$ \\
SSS & \pm 1 \\
SSH & $\pm 1 \mathrm{~m}$ \\
Temperature & $\pm 5^{\circ} \mathrm{C}$ \\
Salinity & \pm 2 \\
\hline Assimilation period & $2015.07 .07-2016.12 .31$ \\
\hline
\end{tabular}


Table 4: Schematic summarizing the evaluation of the geostrophic balance and accuracy of the AVISO SSH and SSHA, the surface zonal and meridional velocity from the drifter buoys, and the temperature and salinity at the KEO buoy in the sensitivity experiments. Open circles and crosses indicate improvement and degradation relative to the NO INFL experiment, and light red and blue shading denotes significant improvement and degradation, respectively. In rows two to four, symbols and color shading are used only if both variables have the same results; otherwise, dashes are used to indicate no significant difference from the NO INFL experiment. Parentheses in the RTPP+IAU and RTPS+IAU experiments denote the best relaxation parameter in the second row and the range of the relaxation parameter with significant improvement in the other rows.

\begin{tabular}{cccccc}
\hline & IAU & RTPP09 & RTPS09 & RTPP+IAU & RTPS+IAU \\
\hline $\begin{array}{c}\text { Geostrophic balance } \\
\text { SSH and SSHA } \\
\text { from the AVISO }\end{array}$ & 0 & $\times$ & $\times$ & (Sig. at $\left.\alpha_{R T P P} \leq 0.9\right)$ & (Sig. at $\left.\alpha_{R T P S} \leq 0.8\right)$ \\
\hline $\begin{array}{c}\text { Surface velocity } \\
\text { from the drifter buoys }\end{array}$ & $\times$ & 0 & 0 & $\left(\right.$ Best at $\left.\alpha_{R T P P}=0.8\right)$ & (Best at $\left.\alpha_{R T P S}=1.1\right)$ \\
\hline $\begin{array}{c}\text { T and S } \\
\text { at the KEO buoy }\end{array}$ & $\times$ & 0 & 0 & (Sig. at $\left.\alpha_{R T P P}=0.8-1.0\right)$ & (Sig. at $\left.\alpha_{R T P S}=1.0\right)$ \\
\hline
\end{tabular}



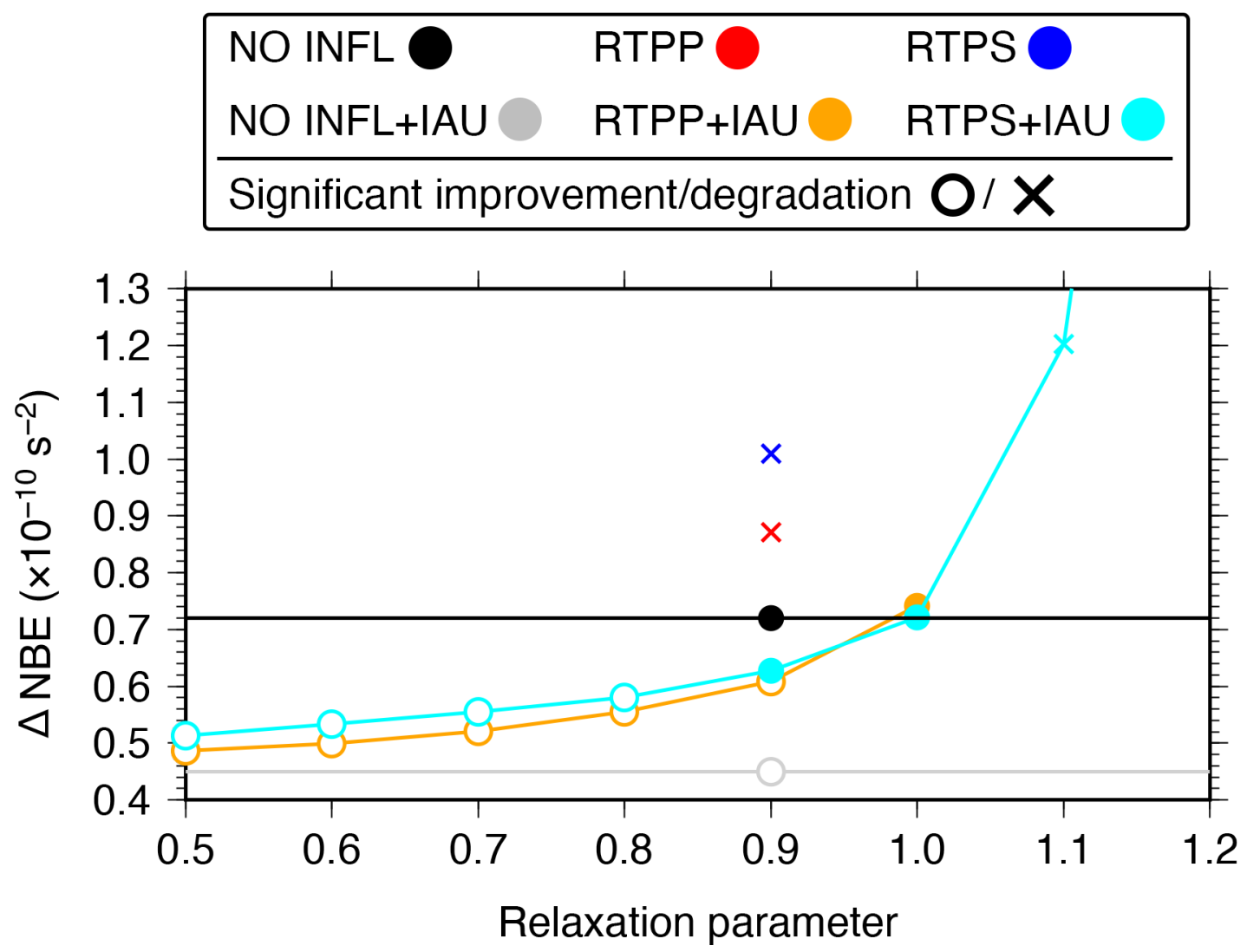

Figure 1: Spatiotemporally averaged $\triangle N B E$ over the whole domain for 2016 in the NO INFL (black), RTPP (red), RTPS (blue), NO INFL+IAU (gray), RTPP+IAU (orange), and RTPS+IAU (cyan) experiments as a function of the relaxation parameters. Open circles and crosses indicate significant improvement and degradation relative to the NO INFL experiment at a 99\% confidence limit, respectively, and closed circles denote no significant differences. The RTPS12+IAU, MULT+IAU, and MULT experiments show significant degradation with average $\triangle N B E$ of 2.94, 2.11, and $5.22 \times 10^{-10} \mathrm{~s}^{-2}$, respectively (not shown). The RTPP+IAU experiments for the relaxation parameters of $\alpha_{R T P P} \geq$ 1.1 are not shown because numerical instability developed. 
(a) NO INFL

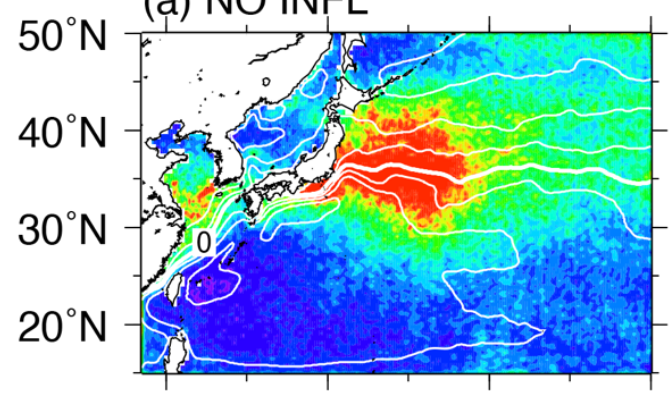

(c) RTPP09

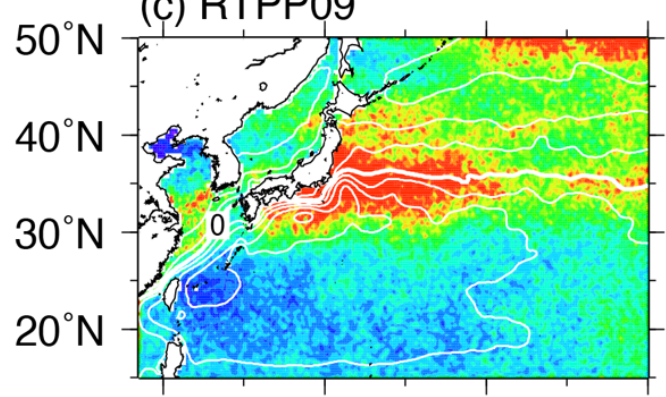

(e) RTPS09

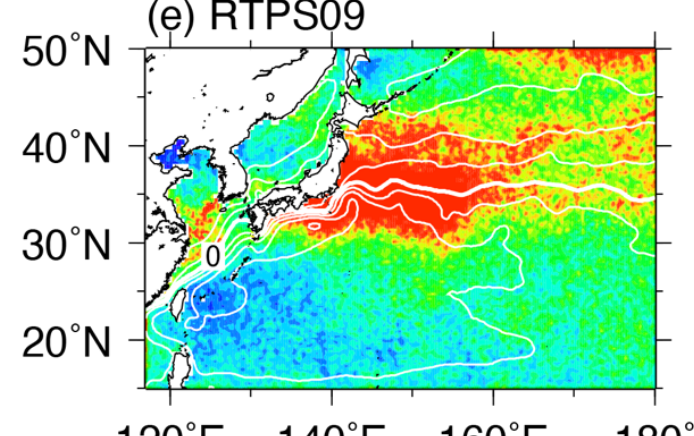

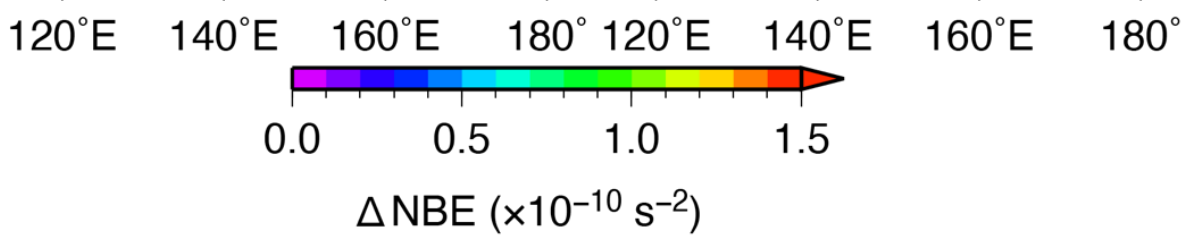

(b) NO INFL+IAU

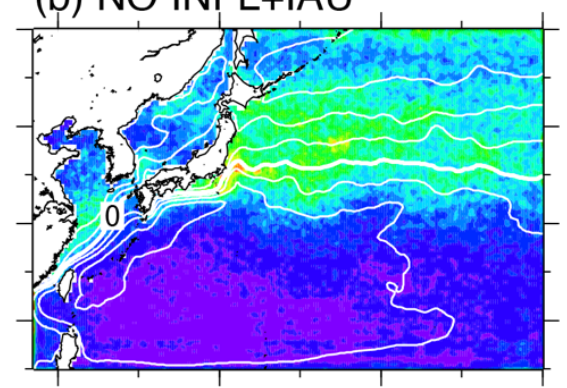

(d) RTPP09+IAU

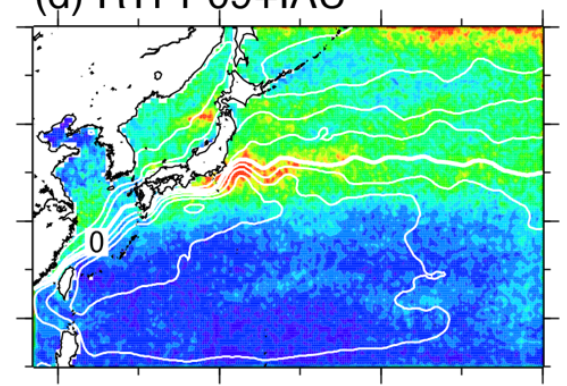

(f) RTPS11+IAU

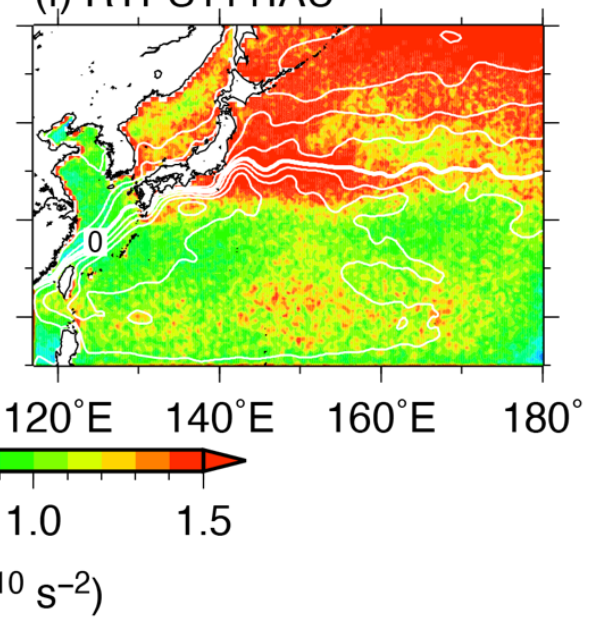

Figure 2: $\triangle N B E$ (colors) and SSH (white contours) averaged over 2016 in the (a) NO INFL, (b) NO INFL+IAU, (c) RTPP09, (d) RTPP09+IAU, (e) RTPS09, (f) RTPS11+IAU experiments. Thin (thick) contour intervals are 0.2 m (1.0 m). 


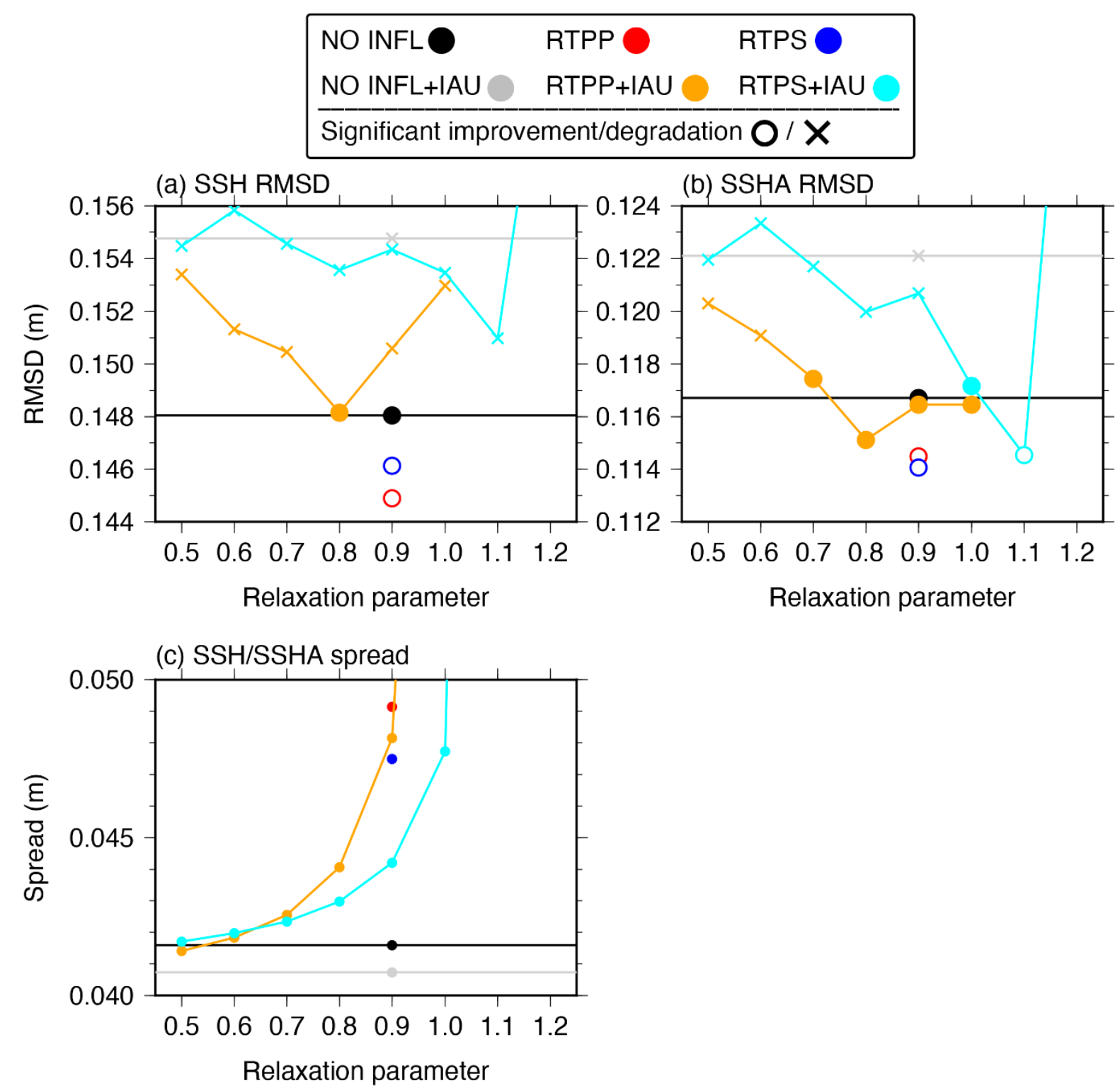

Figure 3: As in Fig. 1 but for the RMSDs of (a) SSH and (b) SSHA relative to the AVISO dataset and (c) ensemble spreads of SSH and SSHA in observational space. The RMSDs of SSH and SSHA in the RTPS12+IAU experiment are 0.164 and $0.137 \mathrm{~m}$, respectively (not shown). 


\begin{tabular}{|lll|}
\hline NO INFL $O$ & RTPP & RTPS \\
NO INFL+IAU & RTPP+IAU & RTPS+IAU \\
\hline Significant improvement/degradation $\mathbf{O} / \mathbf{X}$ \\
\hline
\end{tabular}

(a) U RMSD

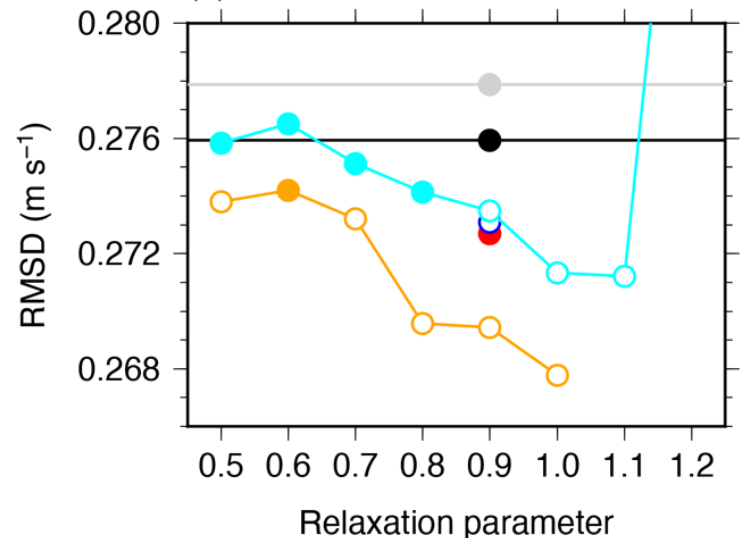

(c) U spread

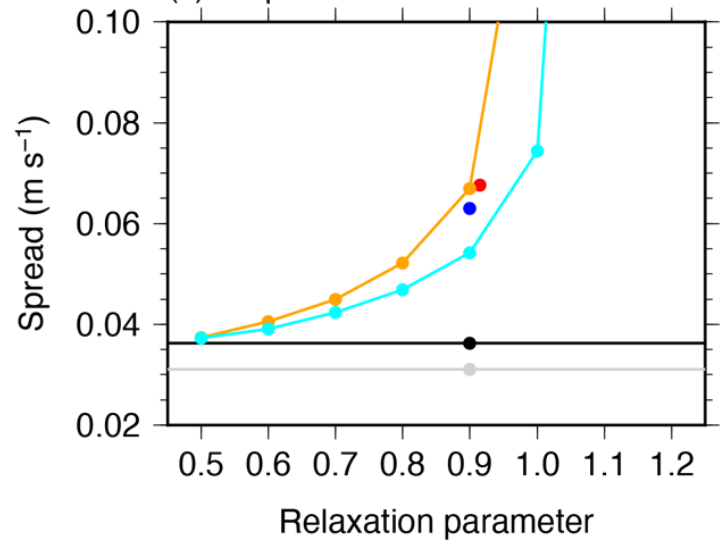

(b) V RMSD

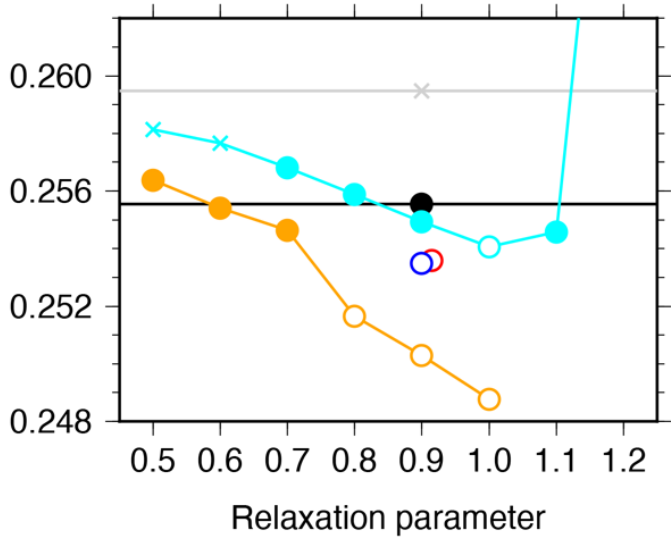

(d) V spread

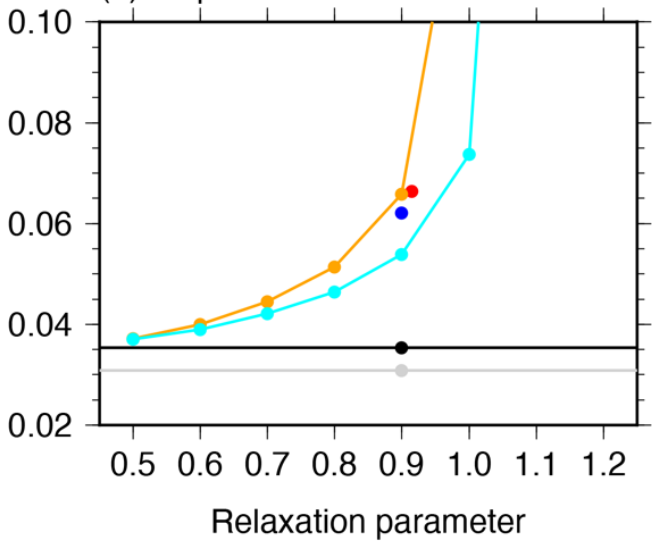

Figure 4: As in Fig. 1 but for the RMSDs of the surface (a) zonal and (b) meridional velocity relative to the drifter buoys, and the ensemble spreads of the surface (c) zonal and (d) meridional velocity. The RMSDs of surface zonal and meridional velocity in the RTPS12+IAU experiment are 0.293 and $0.277 \mathrm{~m} \mathrm{~s}^{-1}$, respectively (not shown). The RMSD in (b) and ensemble spreads in (c) and (d) in the RTPP09 experiment are slightly offset for visualization. 
(b) NO INFL+IAU

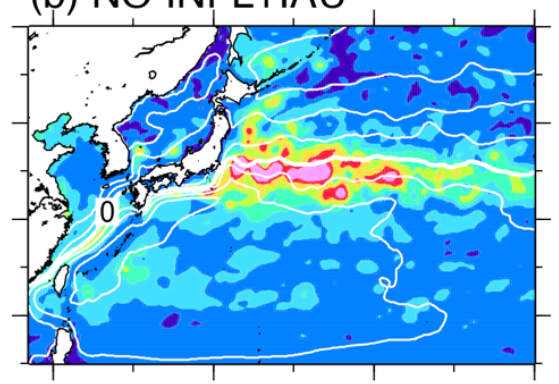

(d) RTPP09+IAU

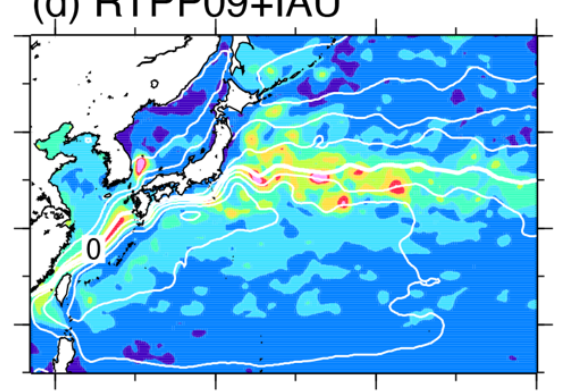

(f) RTPS11+IAU

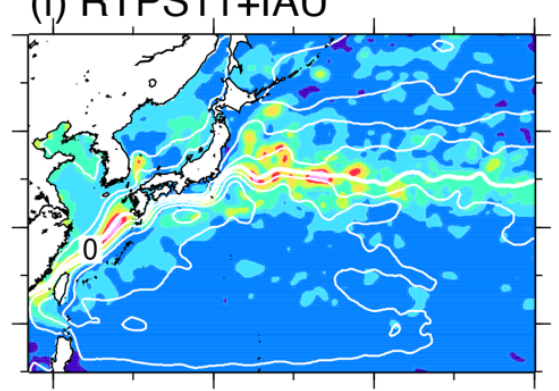

$120^{\circ} \mathrm{E} \quad 140^{\circ} \mathrm{E} \quad 160^{\circ} \mathrm{E} \quad 180^{\circ} 120^{\circ} \mathrm{E} \quad 140^{\circ} \mathrm{E} \quad 160^{\circ} \mathrm{E} \quad 180^{\circ}$

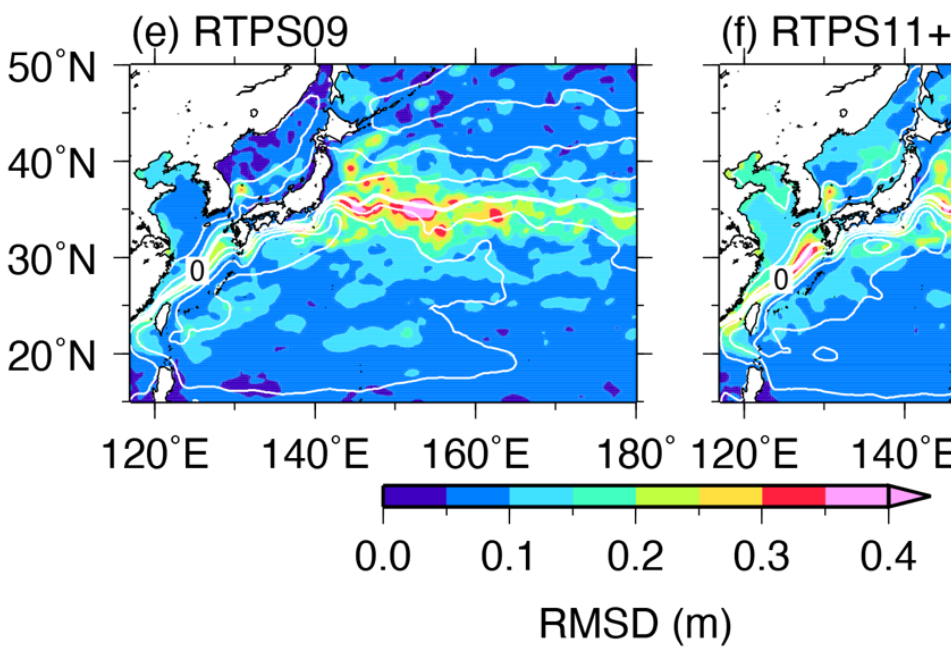

Figure 5: As in Fig. 3, but for the RMSDs relative to the SSHA from the AVISO dataset (color). Black star in (a) indicates the KEO buoy location $\left[144.6^{\circ} \mathrm{E}, 32.3^{\circ} \mathrm{N}\right]$. 
(a) NO INFL

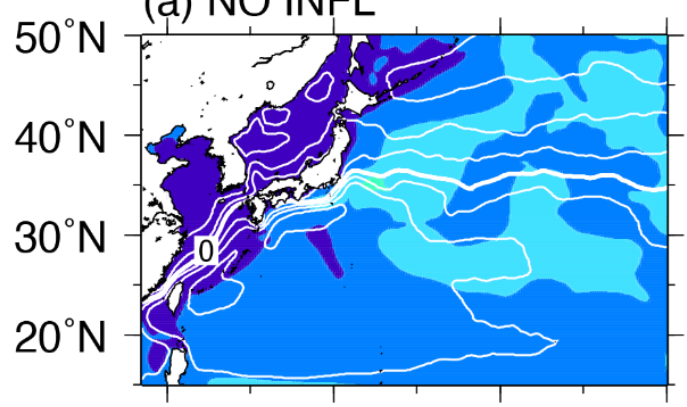

(c) RTPP09

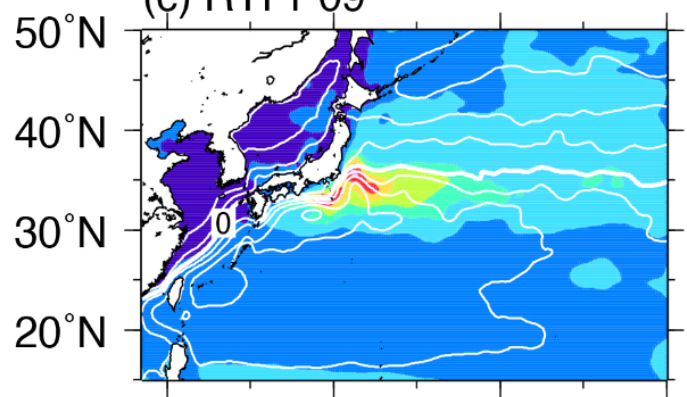

(e) RTPS09

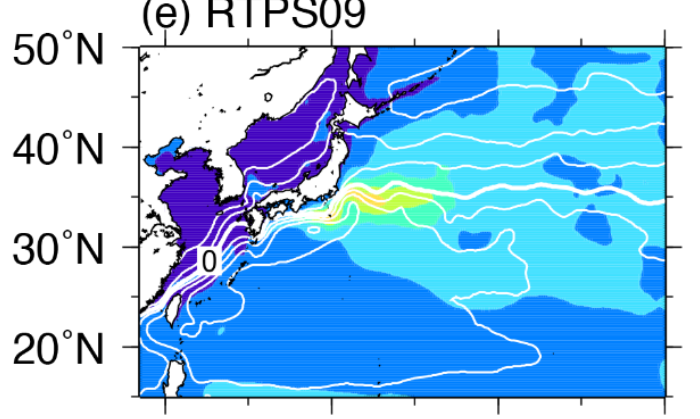

$120^{\circ} \mathrm{E} \quad 140^{\circ} \mathrm{E}$ (b) NO INFL+IAU

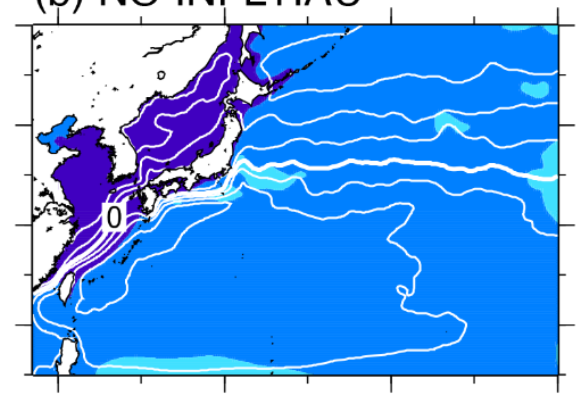

(d) RTPP09+IAU

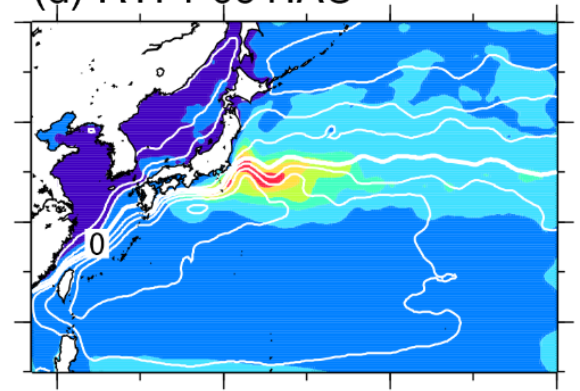

(f) RTPS11+IAU

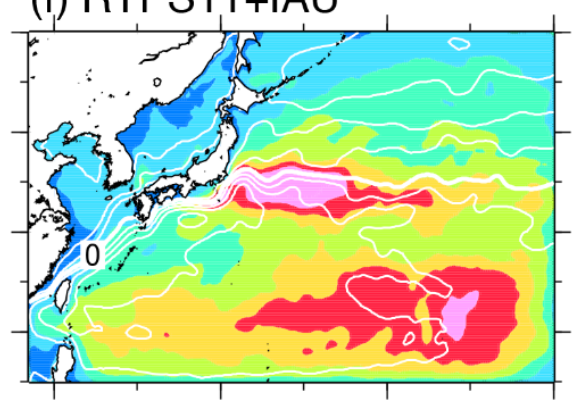

$180^{\circ}$

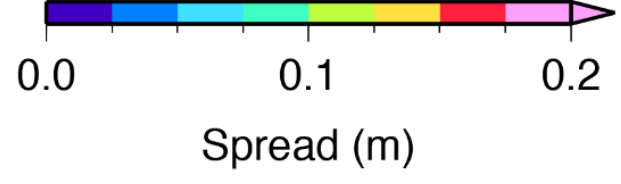

Figure 6: As in Fig. 3, but for the SSHA ensemble spread. 


\begin{tabular}{|lll|}
\hline NO INFL & RTPP09 & RTPS09 \\
NO INFL+IAU $\bigcirc$ & RTPP09+IAU & RTPS11+IAU \\
\hline Significant improvement/degradation $\mathbf{O}$ / $\mathbf{X}$
\end{tabular}
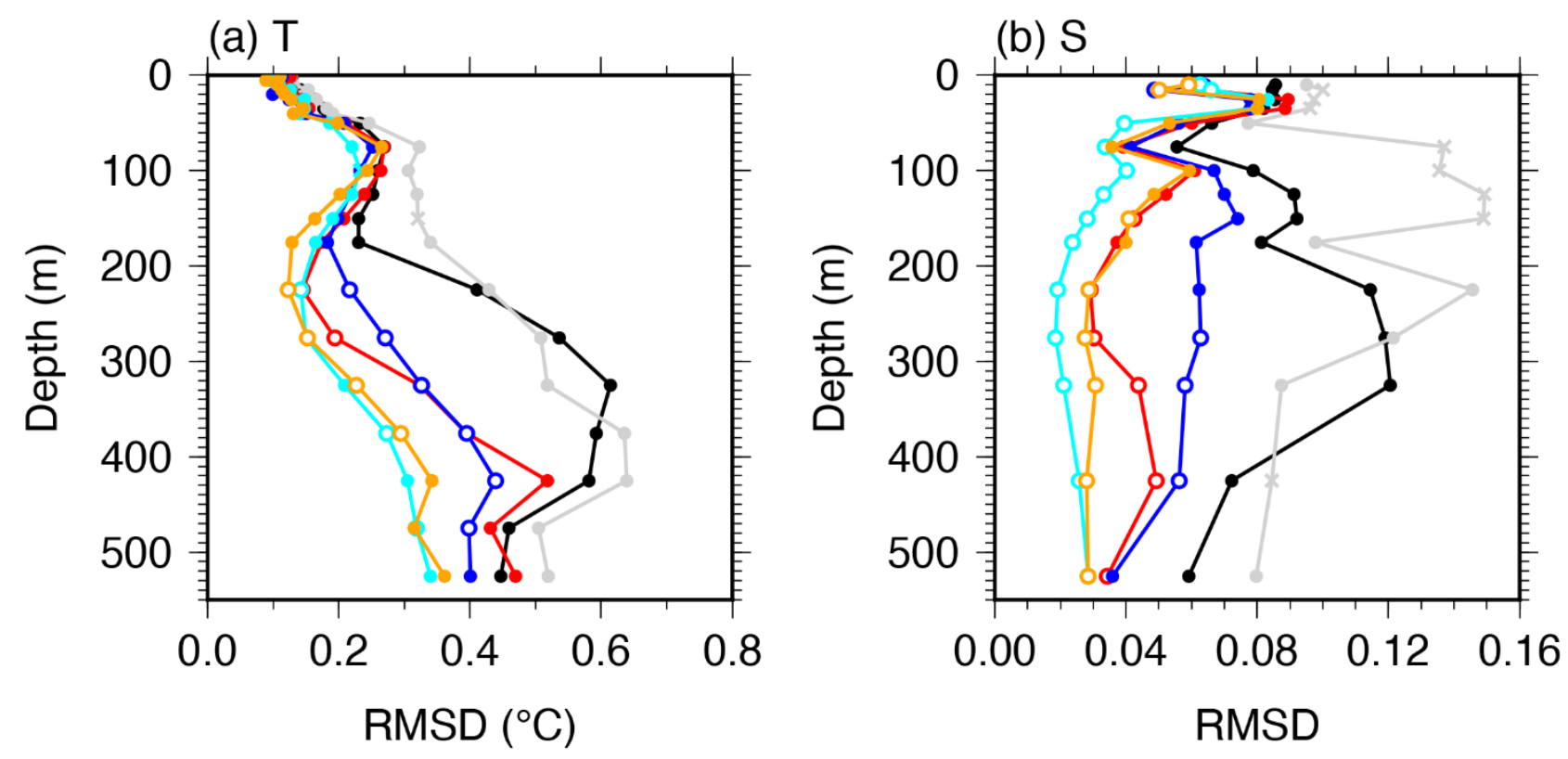

Figure 7: RMSDs of (a) temperature and (b) salinity relative to the KEO buoy averaged over 2016 in the NO INFL

(black), RTPP09 (red), RTPS09 (blue), NO INFL+IAU (gray), RTPP09+IAU (orange), RTPS11+IAU (cyan) experiments. Open circles and crosses denote significant improvement and degradation relative to the NO INFL experiment at a $99 \%$ confidence level, respectively, and closed circles indicate no significant differences. 

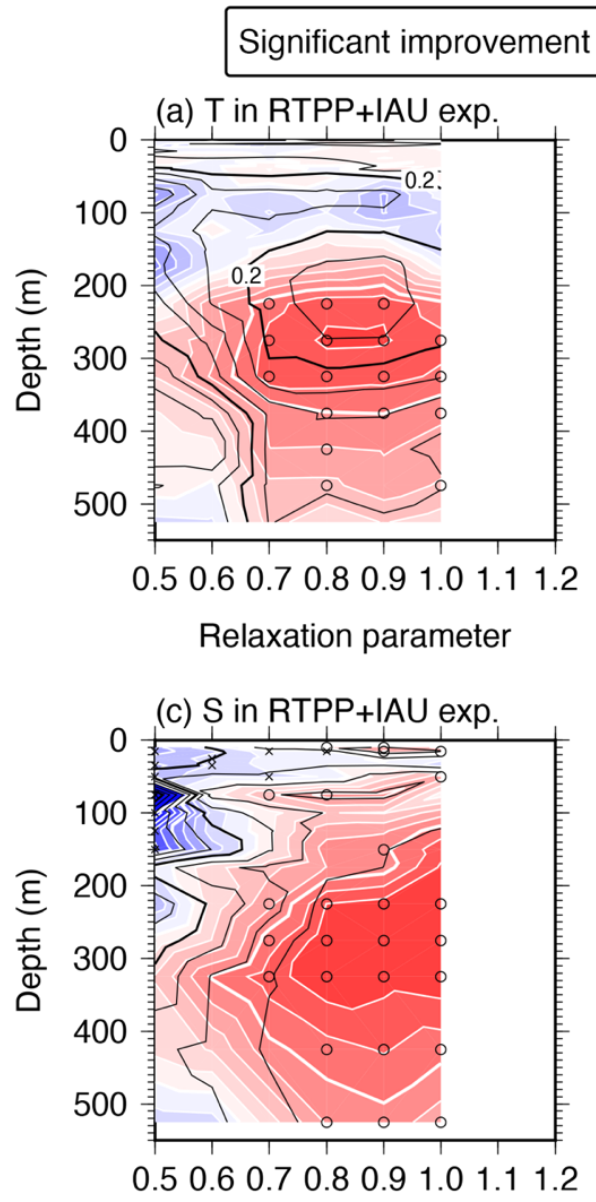

Relaxation parameter
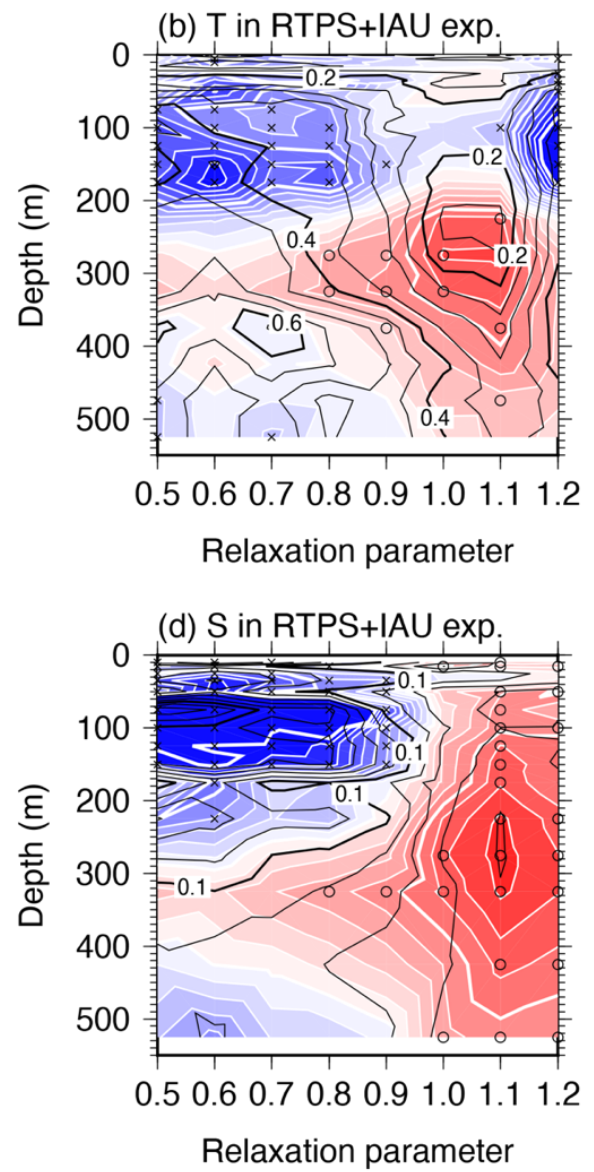

585 Figure 8: Temperature RMSDs (black contours) and IRs (color shading and white contours) between the KEO buoy and (a) RTPP+IAU and (b) RTPS+IAU experiments averaged over 2016. (c) and (d) as in (a) and (b) but for salinity. Open circles and crosses indicate significant improvement and degradation relative to the NO INFL experiment at a $99 \%$ confidence level, respectively. Thin (thick) black contour intervals are $0.05{ }^{\circ} \mathrm{C}\left(0.2^{\circ} \mathrm{C}\right)$ in (a) and (b), and 0.02 $(0.1)$ in (c) and (d); thin (thick) white contour intervals are $10 \%(50 \%)$. 